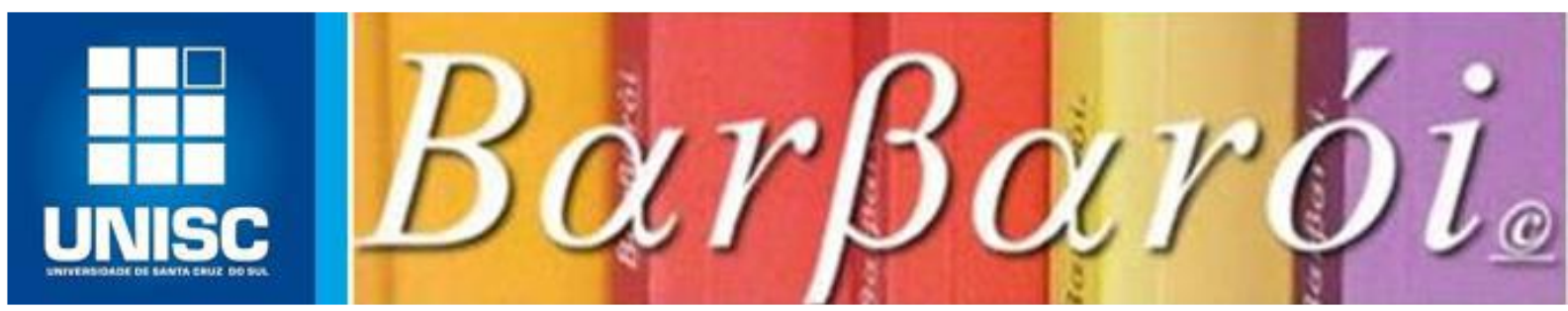

\title{
SERVIÇO SOCIAL E CUIDADOS PALIATIVOS: O QUE SINALIZA A PRODUÇÃO CIENTÍFICA?
}

\author{
DOI: http://dx.doi.org/10.17058/barbaroi.v0i0.14180 \\ $*$ \\ Patricia Barreto Cavalcanti \\ Universidade Federal da Paraíba - UFBP - Brasil \\ Claudenízia de Oliveira Pereira \\ Universidade Federal da Paraíba - UFBP - Brasil
}

Ana Paula Rocha de Sales Miranda

Universidade Federal da Paraíba - UFBP - Brasil

Carla Mousinho Ferreira Lucena

Universidade Federal da Paraíba - UFBP - Brasil

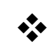

\section{Resumo}

Trata-se de um artigo cujo objetivo central foi mapear a produção científica do Serviço Social em relação aos Cuidados Paliativos com base na consulta em periódicos e simultaneamente, identificar as articulações temáticas presentes em tal produção. A pesquisa foi do tipo exploratória, utilizando-se de uma revisão integrativa. O critério de inclusão, foi o de artigos publicados em periódicos Qualis A1; A2 e B1 do Serviço Social, em português, com textos completos disponíveis online na base de dados eletrônica Scielo, entre os anos de 2005 a 2018. Os descritores eleitos foram: Cuidados Paliativos e Serviço Social. Foram identificados e analisados 08 artigos. As articulações temáticas identificadas formam uma tríade que perpassa o Serviço Socialversus equipe; Serviço Social versus paciente/família; Serviço Social versus viabilizador de direitos sociais. A escassez da produção científica com os termos adotados no estudo, sinaliza a necessidade de maiores incursões teóricas do Serviço Social sobre os Cuidados Paliativos e suas nuances.

Palavras-chave: Cuidados Paliativos; Serviço Social; Produção Científica

\section{Introdução}

Ao longo do tempo, o modo de enfrentarmos a morte modificou-se e, embora costumemos afirmar que "a morte faz parte da vida", este evento natural ainda causa certo pavor, podendo até ser considerado como "o medo universal". Em geral evitamos falar na finitude da vida e quando o fazemos, colocamos a morte como algo bem longínquo. A morte 
ainda é um tema estigmatizado, apesar de ser algo inevitável e inerente à vida. (SIMÃO et al, 2010)

Esses medos e incertezas se agravam no caso de pacientes que são acometidos por algum tipo de doença crônica e com poucas perspectivas de cura, pacientes que estão em Cuidados Paliativos-CPs. Nesses casos, tanto os pacientes quanto seus familiares enfrentam uma gama de dificuldades ao longo do processo de tratamento, muitas vezes doloroso. Situações de ansiedade, dúvidas, lidar constantemente com a perspectiva da morte e com as preocupações práticas da vida diária como filhos, finanças, documentações, assuntos inacabados, conflitos a serem resolvidos, fazem parte do cenário de quem está em tratamento paliativo.

Nesse contexto, o Assistente Social atua com essas demandas familiares que exigem providências, orientações e encaminhamentos, auxiliando o paciente e família a lidarem com questões de ordem financeira, familiar e social, por vezes fortalecendo e/ou retomando vínculos familiares, amenizando estas e outras dificuldades que possam surgir durante o tratamento paliativo.

Embora a temática dos cuidados paliativos seja extremamente importante, fazem-se necessários novos estudos para seu aprofundamento, a fim de ampliar o conhecimento, principalmente sobre o Serviço Social na atuação em Cuidados Paliativos.

Ressaltamos, ainda, que a atuação do Assistente Social nesta seara ainda é pouco explorada no que se refere à produção científica, mostrando-se incipiente. Tal fato decorre por ser recente a oferta dos serviços paliativos na rede pública de assistência à saúde no Brasil e, por conseguinte, a inclusão do profissional de Serviço Social nas equipes multiprofissionais voltadas especificamente aos Cuidados paliativos.

Isso posto, diante de experiências vivenciadas ao longo de 15 anos atuando como Assistente Social em um hospital oncológico da cidade João Pessoa-PB, convivendo junto a pacientes fora de perspectiva de cura, constatamos a urgência em construir reflexões sobre essa expressão da questão social. Ademais, no decurso do nosso mestrado, ao analisarmos o binômio "humanização e acolhimento" foi possível constatar a relevância da profissão junto as pessoas portadoras de doenças crônicas, muitas delas em processo de terminalidade.

Assim, o objetivo central desse artigo foi mapear a produção científica do Serviço Social em relação aos cuidados paliativos com base na consulta em periódicos e, simultaneamente, identificar as articulações temáticas presentes em tal produção. A questão que norteou o estudo foi: quais as associações temáticas presentes na produção científica do Serviço Social em relação aos Cuidados Paliativos? Trata-se de uma reflexão produto do Barbarói, Santa Cruz do Sul, n. 56, p.<68-83>,jan./jun. 2020 
projeto integrado, intitulado "Cuidados Paliativos e Serviço Social: um debate necessário", em operacionalização no Setor de Estudos e Pesquisas em Saúde e Serviço Social da Universidade Federal da Paraíba.

\section{Desenvolvimento}

\section{Cuidados Paliativos: reflexões conceituais}

Foi na Inglaterra, em 1967, que iniciou-se o movimento da filosofia dos cuidados paliativos a partir da iniciativa de Cicely Mary Strode Saunders (enfermeira, assistente social e médica), que disseminou uma nova maneira de cuidar aos pacientes que vivenciavam a terminalidade e a proximidade com a morte.

Tais cuidados visavam compreender todas as necessidades do paciente (dentro dos limites possíveis), contemplando-o como um ser integral. A palavra paliativo deriva do latim pallium, que significa manto. Tal terminologia denota a ideia principal dessa filosofia: de proteger, amparar, cobrir, abrigar, quando a cura de determinada doença não é mais possível. (HERMES e LAMARCA, 2013)

O conceito de Cuidados Paliativos foi definido em 1990 e atualizado em 2002 pela Organização Mundial de Saúde (OMS), que expandiu tal conceito, enfatizando não somente a questão da qualidade de vida, bem como a questão da prevenção do sofrimento.

\footnotetext{
Cuidados paliativos consistem na assistência promovida por uma equipe multidisciplinar, que objetiva a melhoria da qualidade de vida do paciente e seus familiares, diante de uma doença que ameace a vida, por meio da prevenção e alívio do sofrimento, da identificação precoce, avaliação impecável e tratamento de dor e demais sintomas físicos, sociais, psicológicos e espirituais (ANCP, 2012, p.16)
}

Dessa forma, os Cuidados Paliativos constituem um campo interdisciplinar de cuidados totais, individuais e integrais, visando melhorar a qualidade de vida do paciente sem possibilidades de cura, bem como de seus familiares. Através de avaliação correta e de tratamentos adequados para o alívio da dor e dos sintomas, os CPs proporcionam suporte psicossocial e espiritual, em todos os estágios, desde o diagnóstico de uma doença incurável até o período de luto da família.

O foco passa a ser não mais a doença ou a cura, mas a qualidade de vida do paciente, preconizando um atendimento individualizado, humanizado, com uma comunicação franca com o paciente e sua família, almejando um melhor controle dos sintomas físicos, psicológicos, sociais, espirituais, e a prevenção do sofrimento.

Importa salientar que no Brasil é recente a adoção de programas e serviços voltados para este campo de atendimento, estando essa rede de assistência ainda em fase de construção. 
Levando em consideração que a população brasileira está envelhecendo a passos exponenciais, e que esse envelhecimento é um causador de doenças que reduzem a capacidade funcional, bem como gerador de alto índice de doenças crônico degenerativas, essa morosidade em implantar programas e construir uma rede pública de CPs, é preocupante.

(ANDRADE, 2007)

\section{Serviço Social na perspectiva dos Cuidados Paliativos}

No momento que o paciente e seus familiares estão diante de um diagnóstico de uma doença crônica, que não há mais perspectiva de cura, iniciará uma trajetória de enfrentamento de muitas dificuldades, incertezas e medos. Diante dessas demandas tão complexas e, para que a assistência paliativa seja realizada de forma integral e qualificada, o trabalho multiprofissional é de extrema importância, tanto na atenção ao usuário, quanto aos familiares e rede de apoio em geral.

Destacamos que uma equipe especializada e capacitada nesse tipo de cuidado proporciona ao usuário e familiares um atendimento humano e integral. Assim, essa abordagem que visa à dignidade humana, sugerida pelos cuidados paliativos, prioriza uma equipe multiprofissional que deve ser composta por médico, enfermeiro, assistente social, nutricionista, psicólogo, farmacêutico, fisioterapeuta, fonoaudiólogo, cirurgião dentista, terapeuta ocupacional e assistente espiritual. (ANCP, 2012)

Enquanto membro dessa equipe multiprofissional, o Assistente Social atende a essas demandas que surgem nesse processo de adoecimento/morte, como destacado pelo CFESS na resolução $\mathrm{N}^{\circ} 557 / 2009$, que ressalta que

[...] sua atuação conjuntamente com outros profissionais, buscando compreender o indivíduo na sua totalidade e, assim, contribuindo para o enfrentamento das diferentes expressões da questão social, abrangendo os direitos humanos em sua integralidade, não só a partir da ótica meramente orgânica, mas a partir de todas as necessidades que estão relacionadas à sua qualidade de vida. (CFESS, 2009, p.1)

A produção literária acerca desse singular campo de atuação profissional (como já informamos anteriormente) se apresenta restrita, destacando-se as produções de Simão (2010); Andrade (2012); Frossard (2016); Mello et al (2018). Em tais análises, os autores são uníssonos em afirmarem a relevância do profissional de Serviço Social na produção do cuidado em saúde em relação aos pacientes terminais.

Nessa perspectiva, essa atuação se dá através do diálogo com a instituição contratante, equipe multiprofissional, paciente e família, articulando redes de suporte social, formais e 
informais, bem como compreender a rede de relações em que o usuário circunscreve, seja ela familiar, cultural, social ou econômica.

Ao traçar um perfil socioeconômico com informações sobre a composição familiar, local de moradia, renda familiar, religião, formação, profissão, situação empregatícia do paciente e rede de suporte social, proporciona a aproximação com a realidade dos usuários, sendo possível a identificação das suas necessidades sociais.

O Assistente Social analisa o contexto de vida do usuário, no intuito de refletir sobre suas condições sociais e garantir o acesso aos direitos sociais que influenciam no processo de saúde e doença dos usuários e sua rede de apoio (SILVA, 2010).

Frente as necessidades do paciente em fase final de vida, a escuta e acolhida se tornam ferramentas indispensáveis no trabalho, visando o resgate da autonomia do paciente e favorecendo o ambiente e condições mais dignas, desta forma:

\begin{abstract}
A atuação do assistente social em equipes de atenção paliativa pode ser resumida em: conhecer paciente, família e cuidadores nos aspectos socioeconômicos, visando ao oferecimento de informações e orientações legais, burocráticas e de direitos, imprescindíveis para o bom andamento do cuidado ao paciente, e para a garantia de morte digna. Cabe a esse profissional também avaliar a rede de suporte social dos envolvidos, para junto a estes acioná-la em situações apropriadas; conhecer e estabelecer uma rede intrainstitucional, no intuito de garantir atendimento preciso ao paciente, além de constituir-se como interlocutor entre paciente/família e equipe nas questões relacionadas aos aspectos culturais e sociais que envolvem o cuidado de forma geral (ANCP, 2012, p. 221)
\end{abstract}

Nesse sentido, é importante que o profissional tenha conhecimento sobre a profissão, a política social, a instituição em que se insere e a rede de serviços existente, devendo atuar de forma a atender as necessidades sociais, que se transformam em demandas para o profissional, sabendo fazer uma análise de toda a conjuntura na qual está inserida (MARQUES, 2016).

Conforme afirma Frossard (2016), pode-se perceber que o assistente social contribui com a decodificação da realidade social do paciente frente à equipe potencializando a atuação conjunta. Sistematizar as experiências vividas na prática cotidiana dos serviços é tão importante quanto planejar as atividades, configurando-se como um dos principais instrumentos para refletir sobre o trabalho desenvolvido, conformando uma prática realmente científica e capaz de organizar processos de trabalho articulados à dimensão formativa no serviço social.

\title{
Procedimento metodológico
}

Trata-se de um estudo exploratório, tipo revisão integrativa de literatura realizada no período de maio a julho do ano em curso, através de artigos selecionados de periódicos Qualis 
A1, A2 e B1 da área de Serviço Social, através do seguinte banco de dados: o SCIELO (Scientific Electronic Library Online). Foram utilizados, para busca dos artigos, os seguintes descritores e suas combinações na língua portuguesa: Cuidados Paliativos e Serviço Social. Os descritores foram combinados entre si por meio dos conectores booleanos "AND" e "OR".

Os critérios de inclusão definidos para a seleção dos artigos foram: artigos publicados em português, artigos na íntegra que expusessem a temática central deste estudo e artigos publicados e indexados no banco de dados anteriormente mencionado, considerando o lapso temporal de 2005 a 2018, quando ocorre a criação da Academia Nacional de Cuidados Paliativos (ANCP) no país e se constata legalmente inclusão de conteúdos relacionados aos Cuidados Paliativos. A coleta se realizou no período de maio à Julho do ano em curso.

Vale ressaltar que, durante a busca inicial, foram identificados 18 artigos que abordavam a atuação do Assistente Social inserido na equipe multiprofissional. Contudo, apenas 08 artigos foram eleitos para o estudo, pois tratavam especificamente da atuação do Assistente Social junto aos CPs. Portanto, foram selecionados 08 artigos para a amostra final desta revisão integrativa.

A técnica que foi utilizada para sistematização e análise dos dados coletados se baseou na proposta de Lima e Mioto (2007), segundo as quais a mesma possui 4 momentos: leitura de reconhecimento e exploração do material (leitura rápida para identificar o material que pode interessar à temática); leitura seletiva (definir o material que realmente interessa); leitura crítica ou reflexiva (estudo crítico do material, buscando compreender as informações ali contidas) e leitura interpretativa (interpretar os dados colhidos, estabelecendo uma correlação entre os elementos extraídos da obra com o objeto de estudo a que se destina a pesquisa).

Os resultados e análises serão apresentadas em quadros sinópticos, bem como em reflexões sobre fragmentos dos artigos selecionados para uma discussão mais acurada, em cotejo com o objetivo deste trabalho.

\section{Resultados e discussões}

A produção científica acerca do Serviço Social junto aos cuidados paliativos de fato ainda se mostra incipiente e carente de maior densidade. A esse respeito, Martins e Hora (2018) corroboram com tal afirmação e atestam que o Cuidado Paliativo, além de ser uma temática pouco estudada pela categoria, carece de reflexões que se operem de modo crítico. Acrescentamos, ainda, que é necessário dar mais consistência as produções articulando-as as questões de ordem teórico-metodológica da profissão.

Barbarói, Santa Cruz do Sul, n. 56, p.<68-83>,jan./jun. 2020 
Na acepção de Figueredo;

Discorrer sobre o processo de construção do conhecimento científico do Serviço Social brasileiro, além de se constituir num desafio, demanda demarcar alguns parâmetros dado a amplitude do tema. A literatura da área inclusive é fértil em relação aos aspectos relacionados à temática. Autores importantes como Kameyama (1998); Iamamoto (1998); Simionato (2005); Carvalho \& Silva (2005); Setubal (2009) e mais recentemente Nóbrega \& Fonseca (2010); Mauriel \& Guedes (2013); Prates (2013) têm discutido as várias nuances que envolvem o debate, seja se debruçando sobre a qualidade e viés teórico-metodológico predominante no material historicamente produzido, seja refletindo o papel que a pesquisa assume na profissão. (FIGUEREDO, 2017, p. 48)

Destarte, nomeadamente em se tratando de reflexões sobre os Cuidados Paliativos, a residualidade tanto se justifica pela emergência recente dos serviços públicos de saúde voltados para os CPs no Brasil, quanto pela escassa problematização da categoria de Assistentes Sociais em relação as competências e habilidades requeridas nesse campo de atuação.

No decurso deste estudo, fizemos levantamento bibliográfico nos períódicos que seguem na Tabela abaixo:

TABELA 01- Demonstrativo de periódicos pesquisados e Qualis

\begin{tabular}{cc}
\hline PERÍODICOS & QUALIS \\
\hline Kerviço Social \& Sociedade & A1 \\
\hline Textos \& Contextos (Porto Alegre) & A1 \\
Revista de Políticas Públicas da UFMA & A1 \\
Em Pauta & A1 \\
Argumentum (Vitória) & A2 \\
Ser Social & A2 \\
Serviço Social em Revista & A2 \\
Temporalis & A4 \\
Emancipação (Online) ( Ponta Grossa) & A4 \\
Revista Barbarói & A4 \\
O Social em Questão & B1 \\
Sociedade em Debate & B2 \\
\hline
\end{tabular}

Fonte: Primária, 2019

Barbarói, Santa Cruz do Sul, n. 56, p.<68-83>, jan./jun. 2020 
Salientamos que, no caso da produção científica no contexto do Serviço Social, os periódicos ganham relevância por se constituírem no lócus mais importante para escoar a produção e lhe dar visibilidade, assim como, possibilitar a mesma de circular com maior abrangência.

O processo de coleta apontou uma frequência tímida de publicações que possuem os descritores definidos para o estudo, como é possível identificar na Tabela que segue:

TABELA 02- Relação de periódicos e frequência de artigos com descritores

\begin{tabular}{cc}
\hline PERÍODICOS & $\mathbf{N}^{\mathbf{0}}$ DE ARTIGOS ENCONTRADOS \\
\hline Textos \& Contextos & 02 \\
Revista de Políticas Públicas da UFMA & 01 \\
Sociedade em Debate & 02 \\
Revista Katálisys & 02 \\
Revista Serviço Social e Sociedade & 01 \\
TOTAL & $\mathbf{0 8}$ \\
\hline
\end{tabular}

Fonte: Primária, 2019

Como é possível comprovar no quadro supra citado, foram encontrados 08 artigos que se referiam direta ou indiretamente aos descritores selecionados. Tal contexto de pouca produção pode ser analisado tomando como referência os anos de publicação, como é possível verificar no Tabela que segue:

TABELA 03-Quadro Demonstrativo com Periódico e Ano de Publicação

\begin{tabular}{cc}
\hline PERÍODICOS & ANO DE PUBLICAÇÃO \\
\hline Revista de Políticas Públicas da UFMA & 2010 \\
Revista Serviço Social e Sociedade & 2010 \\
Revista Katálisys & 2014 e 2016 \\
Textos \& Contextos & 2014 e 2015 \\
Sociedade em Debate & 2014 e 2017 \\
\hline
\end{tabular}

Fonte: Primária, 2019 
A questão temporal é importante para explicitar a frequência das publicações sobre CPs e Serviço Social. Note-se que as primeiras publicações contendo os descritores selecionados datam de 2010. Tal fato decorre da emersão das primeiras iniciativas estatais em torno da organização dos serviços de CPs no Brasil, pois como prescuta Frossard (2016), foi a partir dos anos 2000 que tais serviços tiveram crescimento no país, embora a autora informe que tal expansão tenha ocorrido de modo desigual, concentrando-se na Região Sudeste e longe de se constituir em serviços universais em se tratando do direito à saúde. Recordamos que a fundação da Academia Nacional de Cuidados Paliativos (ANCP) ocorreu em 2005, o que corrobora com nossa argumentação.

Em prosseguimento ao tratamento dos dados e fazendo uso da proposta metodológica de Lima e Mioto (já mencionadas anteriormente), salientamos que, descartamos 08 artigos que não tratavam diretamente da temática central deste estudo e concluímos pela seleção dos artigos que seguem na Tabela abaixo para análise qualitativa.

TABELA 04- Síntese dos periódicos e Artigos Arrolados no Estudo

\begin{tabular}{|c|c|}
\hline PERÍODICOS & NOME DO ARTIGO \\
\hline Revista de Políticas Públicas da UFMA & $\begin{array}{l}\text { Crianças e Adolescentes em Cuidados } \\
\text { Paliativos Oncolóicos: a intervenção do } \\
\text { Serviço Social junto às suas famílias }\end{array}$ \\
\hline Textos \& Contextos & $\begin{array}{l}\text { Acolhimento e Acesso aos Direitos Sociais: } \\
\text { assistência a pacientes em cuidados paliativos } \\
\text { oncológicos } \\
\text { O Suporte à Família em Cuidados Paliativos }\end{array}$ \\
\hline Sociedade em Debate & $\begin{array}{l}\text { Trabalho do Assistente Social em Equipes } \\
\text { multiprofissionais em Cuidados Paliativos } \\
\text { Trabalho, Direitos e (des)proteção Social: a } \\
\text { realidade do familiar que excerce o cuidado } \\
\text { da criança com Câncer }\end{array}$ \\
\hline \multirow[t]{2}{*}{ Revista Serviço Social e Sociedade } & $\begin{array}{c}\text { Atuação do Serviço Social junto a Pacientes } \\
\text { Terminais }\end{array}$ \\
\hline & $\begin{array}{c}\text { Política de Saúde e de Cuidados Continuados } \\
\text { Integrados em Portugal:o planejamento da } \\
\text { alta em Serviço Social }\end{array}$ \\
\hline
\end{tabular}


Experiência da residência multiprofissional em serviço social e cuidados paliativos oncológicos

Fonte: Primária, 2019

Após leituras sucessivas dos artigos selecionados para a presente revisão e o agrupamento de informações, foi possível construir um consolidado e identificar as abordagens temáticas e suas articulações.

TABELA 05- Identificação das Articulações Temáticas no Contexto dos Cuidados Paliativos e Serviço Social

\begin{tabular}{|c|c|c|}
\hline PERÍODICOS & NOME DO ARTIGO & $\begin{array}{c}\text { ARTICULAÇÕES } \\
\text { TEMÁTICAS }\end{array}$ \\
\hline $\begin{array}{l}\text { Revista de Políticas } \\
\text { Públicas da UFMA }\end{array}$ & $\begin{array}{l}\text { Crianças e Adolescentes em } \\
\text { Cuidados Paliativos } \\
\text { Oncolóicos: a intervenção do } \\
\text { Serviço Social junto às suas } \\
\text { famílias }\end{array}$ & $\begin{array}{l}\text { Trabalho em equipe e } \\
\text { Direitos sociais }\end{array}$ \\
\hline Textos \& Contextos & $\begin{array}{l}\text { Acolhimento e Acesso aos } \\
\text { Direitos Sociais: assistência a } \\
\text { pacientes em cuidados } \\
\text { paliativos oncológicos; } \\
\text { O Suporte à Família em } \\
\text { Cuidados Paliativos }\end{array}$ & $\begin{array}{l}\text { A Social como } \\
\text { viabilizador de } \\
\text { Direitos } \\
\\
\text { Aspecto psicosocial, } \\
\text { detector de } \\
\text { problemas, } \\
\text { levantamento e } \\
\text { avaliação de } \\
\text { necessidades }\end{array}$ \\
\hline & $\begin{array}{c}\text { Trabalho do Assistente Social } \\
\text { em Equipes multiprofissionais } \\
\text { em Cuidados Paliativos; }\end{array}$ & Trabalho em equipe \\
\hline Sociedade em Debate & $\begin{array}{l}\text { Trabalho, Direitos e } \\
\text { (des)proteção Social: a } \\
\text { realidade do familiar que } \\
\text { excerce o cuidado da criança } \\
\text { com Câncer }\end{array}$ & Direitos sociais \\
\hline $\begin{array}{c}\text { Revista Serviço Social e } \\
\text { Sociedade }\end{array}$ & $\begin{array}{l}\text { Atuação do Serviço Social } \\
\text { junto a Pacientes Terminais }\end{array}$ & Direitos sociais \\
\hline \multicolumn{3}{|c|}{$\begin{array}{l}\text { Política de Saúde e de } \\
\text { Cuidados Continuados }\end{array}$} \\
\hline
\end{tabular}




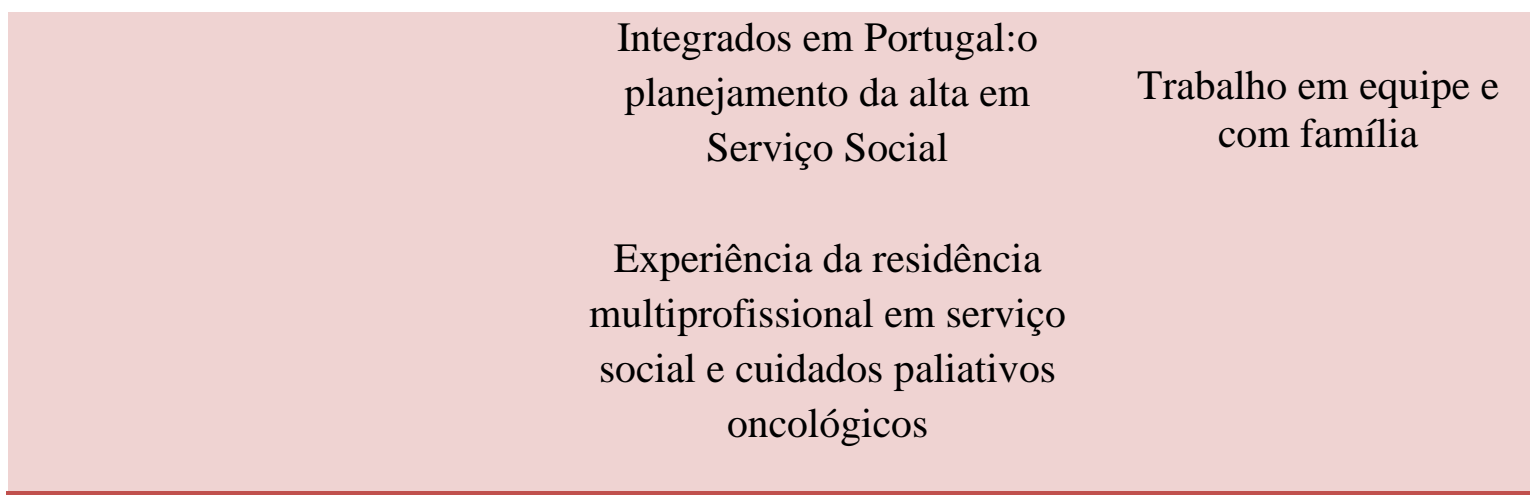

Fonte: Primária, 2019

Analisando qualitativamente os fragmentos da produção mapeada, observamos que, em se tratando do tema "Assistente Social como Viabilizador de Direitos", a reflexão da autora que segue em análise, se coaduna com o Projeto Ético Político da Profissão (PEP), bem como com os Parâmetros de Atuação dos Assistentes Sociais na Saúde. É possível constatar no trecho abaixo uma perspectiva embasada nos preceitos éticos defendidos pelo Serviço Social.

\begin{abstract}
"Dentre essas demandas, destaca-se o acesso ou não a direitos sociais garantidos por lei. O assistente social, nesse contexto, enquanto profissional com competências para tal, tem o papel de escutar as necessidades desses pacientes, orientando-os, assim como a seus familiares, sobre como devem proceder para acessar os direitos sociais e acompanhar as demandas.”(MEDEIROS et al. 2015, p. 4007)
\end{abstract}

Pautando-se nos Parâmetros para a Atuação dos Assistentes Sociais na Saúde, tem-se que uma atuação competente e crítica consiste, entre outras coisas, em "[...] facilitar o acesso de todo e qualquer usuário aos serviços de saúde da instituição e da rede de serviços e direitos sociais [...]”, sendo umas das ações desenvolvidas pelo profissional, a democratização de informações através de orientações e/ou encaminhamentos quanto aos direitos sociais da população. (CFESS, 2010, p. 45).

Nesse sentido, cabe ao Assistente Social conhecer o usuário e sua rede de apoio, visando oferecer informações que possam contribuir para viabilização e acesso aos seus direitos e políticas sociais. Salientamos que as necessidades de saúde vão além do nível de acesso aos serviços e tratamentos médicos, são produtos das relações sociais e destas com o meio físico, social e cultural. (NOGUEIRA e MIOTO, 2006)

As demandas sociais emergem de diferentes formas durante a ação profissional. Assim sendo, as intervenções abrangem desde as mudanças que ocorrem no cotidiano do usuário e de seus familiares devido aos diagnósticos, doenças, tratamento, a dificuldade do acesso ao tratamento médico; até as questões relacionadas aos Direitos Sociais e Proteção Social, as quais muitas vezes, só são identificadas quando a pessoa adoece (NARCISO, 2005. p. 6). 
Uma outra articulação temática detectada foi relacionar cuidados paliativos, Serviço Social e trabalho em equipe, partindo do suposto de que é na perspectiva multiprofissional que o Assistente Social tem materializado sua atução no contexto dos CPs.

O trabalho multiprofissional com usuários que estão em cuidados paliativos requer a integração de saberes e das práticas em saúde. O Serviço Social insere-se, principalmente, em ações que fomentam a autonomia dos usuários no processo terapêutico, oportunizando a reflexão sobre os aspectos que perpassam o seu diagnóstico. Em uma intervenção em equipe multidisciplinar, o Assistente Social assume o papel de mediador e facilitador entre paciente/família/equipe, procurando, dentro das respostas, a que melhor promover o bem-estar do paciente. Em um dos artigos selecionados para análise, os autores atestam que, em equipe,

\begin{abstract}
“...o assistente social terá como principais funções participar no plano de ação de cada caso individual, estabelecendo prioridades de trabalho de ordem assistencial, investigação e docência, fornecendo ao grupo feedback dos conhecimentos que possui. Deve ainda apresentar e trabalhar respostas sociais disponíveis na comunidade, consoante as necessidades detectadas quer no grupo doente/família quer no próprio grupo de profissionais. Individual e personalizadamente, o assistente social avalia o processo de adaptação à doença e reavalia as preocupações sociofamiliares que vão surgindo, informando, orientando e contactando os recursos pretendidos e acordados." (Reigada et al. 2014, p. 160)
\end{abstract}

Como integrante da equipe de saúde, a função do Assistente Social incide na detecção e levantamento de problemas, bem como na avaliação de necessidades do paciente, estando envolvido em um processo mais subjetivo que envolve os CPs.

Outra articulação temática apontada na pesquisa foi referente aos cuidados paliativos, Serviço Social e suporte familiar. Tais temas insurgem como relevantes na discussão e são sinalizados nos estudos de Cabral et al (2017) e Andrade (2012), já que, segundo as autoras, os Assistentes Sociais devem apoiar suas atuações na interlocução entre família, usuário e equipe, construindo mediações com objetivo de fomentar o uso da rede de apoio tão necessária em momentos de finitude humana.

Um plano terapêutico paliativista a ser escolhido precisa ser discutido entre a equipe, a família e o paciente. O desafio para a equipe multiprofissional, muitas vezes, é entender a família como parte integrante desse processo de cuidados. Nesse sentido, a intervenção do Assistente Social é a de dar voz a esses pacientes e familiares. Tal assertiva pode ser detectada no trecho abaixo, de um dos artigos analisados:

"Dentro dessa lógica, é no contato do assistente social com a família, não apenas no início do tratamento, mas no decorrer de todo acompanhamento, que ele identifica inúmeras demandas. Situações socioeconômicas precárias, desavenças familiares, violência doméstica, moradia insalubre, dificuldades de compreensão, transtornos mentais, dificuldade no acesso a serviços de saúde, educação e assistência. A identificação dessas demandas leva o Assistente Social a acionar os recursos 
existentes na sociedade, de modo a dar suporte à família no enfrentamento da situação." (Silva, 2010, p. 143)

Destarte, é necessário articulação constante com diversas políticas sociais em que o paciente/família estão inseridos, tais como Assistência Social, Saúde, Educação, Habitação, Previdência, identificando suas dificuldades, o contexto social, cultural e econômico.

\section{Considerações finais}

A filosofia paliativista valoriza a comunicação franca, a autonomia, a qualidade de vida, o controle de dor e demais sintomas, em uma intervenção multiprofissional. É uma das poucas propostas de saúde que valoriza o trabalho que integra os profissionais, paciente e família com vistas a minimizar o sofrimento e proporcionar qualidade de vida a pacientes que se encontram diante de uma doença ameaçadora à vida.

Como integrante dessa equipe, o Assistente Social exerce significativo papel ao lidar constantemente com os familiares, mediando possíveis conflitos entre equipe multiprofissional, paciente e família, podendo informar para a equipe quem é esse paciente e sua biografia, onde e em quais condições sociais ele está inserido para que possa efetivar o tratamento e, assim, planejar um plano terapêutico e os cuidados necessários a ele e sua família.

Nesse sentido, identificamos que as articulações temáticas envolvidas na produção do conhecimento do Serviço Social em Cuidados Paliativos referem-se a uma tríade que perpassa a Serviço Social X equipe, Serviço Social X paciente / família e Seviço Social X viabilizador de direitos sociais.

Esses achados corroboram com as atribuições do Serviço Social na equipe de cuidados paliativos que estão atreladas à perspectiva de garantia de direito dos usuários e dos seus familiares, viabilizando a efetivação do objetivo dos cuidados paliativos, isto é, garantia de qualidade de vida em seus aspectos físico, emocional, social e espiritual. Destarte, identificamos que mesmo residual, a produção científica relacionando Cuidados Paliativos e Serviço Social apresenta preocupações de ordem teórico-metodológica ao tomar como parâmetro de suas reflexões o PEP e as sinalizações do Conselho Federal de Serviço Social.

A prática do Assistente Social nesta seara ainda é pouco explorada, a literatura também ainda é muito escassa. Essa área de atuação só tende a crescer para o Assistente Social e é essencial que estejamos atentos para lidar e explorar essas demandas emergentes. Assim, espera-se que este artigo possa contribuir para a ampliação e a posteriori para a consolidação do debate. 


\title{
SOCIAL SERVICE AND PALIATIVE CARE: WHAT DOES SIGNALING SCIENTIFIC PRODUCTION?
}

\begin{abstract}
It is an article whose central objective was to map the scientific production of Social Work in relation to Palliative Care based on consultation in journals and, simultaneously, to identify the thematic articulations present in such production. The research was exploratory, using an integrative review. The inclusion criterion was articles published in Qualis A1 journals; A2 and B1 of Social Service, in Portuguese, with full texts available online in the electronic database Scielo, between the years 2005 to 2018. The chosen descriptors were: Palliative Care and Social Service. 08 articles were identified and analyzed. The thematic articulations identified form a triad that runs through the Socialversus Service team; Social Work versus patient / family; Social Work versus social rights enabler. The scarcity of scientific production with the terms adopted in the study, signals the need for greater theoretical incursions by Social Work on Palliative Care and its nuances.
\end{abstract}

Keywords: Palliative Care; Social service; Scientific production

\section{REFERÊNCIAS}

ACADEMIA NACIONAL DE CUIDADOS PALIATIVOS (ANCP). Manual de Cuidados

Paliativos. ampl. E atual. - Porto Alegre: Sulina, 2012.

ANDRADE, L. Trajetórias no limiar da vida e da morte: cuidados paliativos na assistência domiciliar. 2007. 199f. Tese (Doutorado em Serviço Social), Pontífica Universidade Católica de São Paulo, PUC-SP. 2007.

ANDRADE, L. O papel do assistente social na equipe. In: CARVALHO, R. T.; PARSONS, H. A. (Org.) Manual de Cuidados Paliativos . São Paulo: Academia Nacional de Cuidados Paliativos (ANCP), 2012. p.341-345.

CABRAL, Sheilha Beatriz et all. Cuidados paliativos: reflexões acerca da atuação do Assistente Social em âmbito hospitalar. II Seminário Nacional de Serviço Social, Trabalho e Políticas Sociais. Universidade Federal de Santa Catarina Florianópolis -23 a 25 de outubro de 2017.

CONSELHO FEDERAL DE SERVIÇO SOCIAL (CFESS). Parâmetros para atuação de assistentes sociais na política de saúde. Brasília: CFESS, 2010.

CFESS. Resolução $\mathrm{n}^{\circ}$ 557, de 15 de setembro de 2009. Dispõe sobre a emissão de pareceres, laudos, opiniões técnicas conjuntos entre o assistente social e outros profissionais.

FIGUEIREDO, Joacely Carneiro. O Serviço Social e as Expressões da Questão Social do Envelhecimento: análise da produção do Conhecimento nos periódicos da área. Dissertação Mestrado em Serviço Social, UFPB, João Pessoa, 2017.

FROSSARD, Andrea. Os cuidados paliativos como política pública:notas introdutórias. Cad. EBAPE.BR, v.14, Edição Especial, Artigo 12, Rio de Janeiro, Jul.2016. 
HERMES, Hélida Ribeiro; LAMARCA, Isabel Cristina Arruda. Cuidados paliativos: uma abordagem a partir das categorias profissionais de saúde. Ciênc. saúde coletiva [online]. 2013, vol.18, n.9, pp.2577-2588.

LIMA, Telma Cristiane Sasso de; MIOTO, Regina Célia Tamaso. Procedimentos metodológicos na construção do conhecimento científico: a pesquisa bibliográfica. Rev. Katálysis. Florianópolis v. 10 n. esp. p. 37-45 2007.

MARTINS, Gabrieli e HORA, Senir Santos. A intervenção do assistente social em cuidados paliativos: algumas reflexões éticas IN Diálogos em Saúde Pública e Serviço Social: a experiência do assistente social em oncologia / Instituto Nacional de Câncer José Alencar Gomes da Silva; organizado por Ana Raquel de Mello Chaves, Kassia de Oliveira Martins Siqueira, Luciana da Silva Alcantara, e Renata Cristina Mendes Lima. 1. reimp. - Rio de Janeiro: Inca, 2018.

MARQUES, A. A. Plantão Social no Ambulatório de Especialidade do Hospital Universitário: Uma análise das demandas sociais. 2016. 53 fls. Trabalho de Conclusão de Curso (Graduação em serviço social) - Universidade Estadual de Londrina, Londrina, 2016.

MATSUMOTO, Dalva Yukie. Cuidados Paliativos: conceito, fundamentos e princípios. In: CARVALHO, Ricardo Tavares; PARSONS, Henrique Afonseca (Orgs.). Manual de Cuidados Paliativos - ANCP. $2^{\text {a }}$ ed. Porto Alegre: Ed. Sulina, 2012, p. 23-30.

MEDEIROS, T. S. et all. Acolhimento e Acesso aos Direitos Sociais: assistência a pacientes em cuidados paliativos oncológicos. Textos \& Contextos (Porto Alegre), v. 14, n. 2, p. 403 - 415, ago./dez. 2015.

MELLO, Michele Ribeiro Vieira et alli. Uma Análise sobre os Cuidados Paliativos no Serviço Social IN Caderno Humanidades em Perspectivas - I Simpósio de Pesquisa Social e I Encontro de Pesquisadores em Serviço Social - Edição Especial Julho/2018

NARCISO, A. M. S.; MEDINA, M. L. M.; PEREIRA, M. T. M. A. Plano de ações do serviço social HU/HC na epidemia de aids. Hospital Universitário. Divisão de Serviço Social. Londrina. 2005.

NOGUEIRA, V. M. R.; MIOTO, R. C. T. Desafios atuais do Sistema Único de Saúde SUS e as exigências para os assistentes sociais. In: MOTA, E. E. et al. (Org.). Serviço Social e saúde: formação e trabalho profissional. São Paulo: Cortez, 2006. v. 1, p. 218-241.

REIGADA, Carla et all. O Suporte à Família em Cuidados Paliativos. Textos \& Contextos (Porto Alegre), v. 13, n. 1, p. 159 - 169, jan./jun. 2014.

SILVA, Tatiana Silva Camara da. Crianças e Adolescentes em Cuidados Paliativos Oncológicos: a intervenção do Serviço Social junto às suas famílias. R. Pol. Públ. São Luís, v.14, n.1, p. 139-146, jan./jun. 2010

SIMÃO et al. A atuação do Serviço Social juto a pacientes terminais: breves cosiderações. Serv, Soc. Soc., São Paulo, n. 102, p. 352-364, abr/jun. 2010. 
Data de recebimento: $16 / 09 / 2020$

Data de aceite: $21 / 05 / 2020$

\section{Sobre as autoras:}

Patricia Barreto Cavalcanti é Doutora em Serviço Social -PUC/SP; Coordenadora do Setor de Estudos e Pesquisas em Saúde e Serviço Social. Pesquisadora do CNPQ. Endereço Eletrônico: patriciabcaval@gmail.com

Claudenízia de Oliveira Pereira é Mestre em Serviço Social. Especialista em Políticas Públicas. Endereço Eletrônico: claudeniziaopereira@hotmail.com

Ana Paula Rocha de Sales Miranda é Professora Adjunto IIII do departamento de Serviço Social. Docente do Programa de Pós Graduação em Serviço Social da UFPB. Doutora em Serviço Social/PUC-SP. Endereço Eletrônico: aprmiranda2@gmail.com

Carla Mousinho Ferreira Lucena é Mestre em Serviço Social. Especialista em Saúde Hospitalar. Endereço Eletrônico: carlamousi@ hotmail.com 